\section{What matters to patients when their care is delegated to dental therapists?}

\author{
T. A. Dyer, ${ }^{* 1}$ J. Owens ${ }^{2}$ and P. G. Robinson ${ }^{3}$
}
IN BRIEF
- Reports positive views and experiences of care provided by dental therapists.
- Suggests that trust is built on the communication skills and attitude of the dental team (affective behaviour) and continuity of care.
- Reports negative experiences of dental therapist care in cases where communication was poor and continuity of care was lacking.

Aim To explore the experiences of adult patients and parents of child patients when their oral healthcare is delegated to dental therapists. Method Narrative study using semi-structured in-depth interviews of a purposive sample of patients $(n=15)$ and parents of child patients $(n=3)$ who have been treated by therapists. Results Overall, participants reported positive experiences of treatment provided by therapists. Two main themes emerged from the data. The first; perceptions of the nature of dental services appeared related to the second; trust and familiarity in the dental team. Perceptions of the nature of dental services ranged from viewing dentistry as a public service to that of a private service, consistent with a more consumerist stance. Within this theme, three dimensions were identified: rationale for skill-mix; team hierarchy and importance of choice and cost. Consumerist perspectives saw cost reduction, rather than increasing access, as the rationale for skill-mix. Such perspectives tended to focus on hierarchy and a rights-based approach, envisaging dentists as the head of the team and emphasising their right to choose a clinician. Trust in and familiarity with the dental team appeared critical for therapists to be acceptable. Two dimensions were important in developing trust: affective behaviour and communication and continuity of care. Two further dimensions were identified in this theme: experience over qualification and awareness of therapists. Where trust and familiarity existed, participants emphasised the importance of their experiences of care over the qualifications of the providing clinician. Equally, trust in the dentist delegating care appeared to reassure participants, despite awareness of the role of therapists and their training being universally low. Conclusion Regardless of perspective, views and experiences of treatment provided by therapists were positive. However, trust in and familiarity with the dental team appeared critical. Trust was apparently founded on dental teams' affective behaviour, communication skills and continuity of care. There are implications for skill-mix where staff turnover is high, as this is likely to compromise familiarity, continuity of care and ultimately trust.

\section{INTRODUCTION}

The use of skill-mix in UK dentistry has been given increasing prominence over the last two decades. Two influential reports ${ }^{1,2}$ and subsequent legislative change ${ }^{3}$ have led to a new class of dental worker: dualtrained dental hygienists and therapists (described as therapists in this report) who can work in all sectors of dentistry. The number of training places has also greatly increased. The rationale for these changes focuses on the potential to increase patient

\footnotetext{
${ }^{1}$ Honourary Lecturer in Dental Public Health, ${ }^{2}$ Lecturer in Disability and Health, ${ }^{3}$ Professor in Dental Public Health, School of Clinical Dentistry, University of Sheffield, Sheffield, S10 4AT

${ }^{*}$ Correspondence to: Mr Thomas Anthony Dyer Email: t.dyer@sheffield.ac.uk
}

\section{Online article number E17}

Refereed Paper - accepted 7 December 2012

DOI: $10.1038 /$ sj.bdj.2013.275

${ }^{\circledR}$ British Dental Journal 2013; 214: E17 access and the efficiency of dental services. ${ }^{4-6}$ In addition, changes in population treatment need mean that therapists could provide treatment at 70\% of all visits; representing $60 \%$ of all clinical time in UK primary dental care. ${ }^{7}$

A commonly reported concern is the impact of skill-mix on the quality of dental care. ${ }^{8}$ Quality in healthcare is a multidimensional concept, with the efficiency, effectiveness and acceptability of services being key factors. ${ }^{9,10}$ Existing data on efficiency and effectiveness in dentistry suggest that concerns about skill-mix may be unfounded. However, less is known about its acceptability. ${ }^{11,12}$

Assessments of the acceptability of services should consider professional, social acceptability (or legitimacy) and the experiential views of service users. ${ }^{10}$ Our study on the legitimacy and social acceptability of skill-mix sought the views of 1,000 UK adults and identified low levels of awareness and experience of dental therapists. ${ }^{13}$ Although the acceptability of some procedures was relatively high, more invasive procedures and those provided for children were less so. ${ }^{13}$ These findings were consistent with earlier qualitative findings. ${ }^{14}$ Yet high levels of satisfaction have been reported from patients receiving care from dental therapists compared to dentists. ${ }^{11,15}$ The reasons for these differences remain elusive, with the inflexibility of survey methods cited as one reason for this. ${ }^{15}$

The theoretical and methodological difficulties of assessing patient satisfaction are well documented ${ }^{16-18}$ and contemporary approaches recommend qualitative as well as quantitative approaches. ${ }^{18-21}$ Quantitative methods, such as questionnaires, may omit key factors that are important to patients, 
especially where the subject matter is complex and patients' views have not been considered. Consequently they are unlikely to capture the subjectivity of patients and what really matters to them. ${ }^{18,22}$ In-depth interviewing allows the researcher to probe and explore views and experiences and provides patients with a 'voice' that can complement quantitative findings. ${ }^{21,23}$ Qualitative methodology and methods can also be an important precursor to quantitative research as it sheds light on the types of patient experience so that they can be measured. ${ }^{22}$

Consequently the aim of this study was to explore the views and experiences of patients and parents of child patients having oral healthcare delegated to therapists in dental practice.

\section{METHOD}

This was a qualitative study that used a blend of ethnographic and narrative methods. Interviews $(\mathrm{n}=15)$ were undertaken with a purposive sample of adults in South Yorkshire, England between July 2011 and May 2012. Participants were adult patients ( $>16$ years old) who had experienced their care delegated to a therapist who then provided treatment $(\mathrm{n}=15)$. Parents of children $(n=3)$ were also included. A range of treatment was delegated to therapists including scaling, root planing, restorations in adults and children and extraction of first (deciduous) teeth. For reasons of feasibility and practicality, children ( $<16$ years old) were not included.

Recruitment was conducted in six dental practices, which provided a mix of NHS and private dental care to patients from a range of ages, socioeconomic and cultural backgrounds as these factors may influence views and experiences. ${ }^{13,14}$ Practices employing dental therapists were identified via dental practice advisors, local dental committees and the programme in hygiene and therapy at the University Sheffield. Letters of invitation were sent to eight practices and six agreed to participate. At the practices, patients and parents of children were purposively sampled to capture a comprehensive range of views and experiences. ${ }^{22}$

Having consented to participate, data were collected at a venue of participants' choosing and convenience in natural surroundings away from the clinical setting,

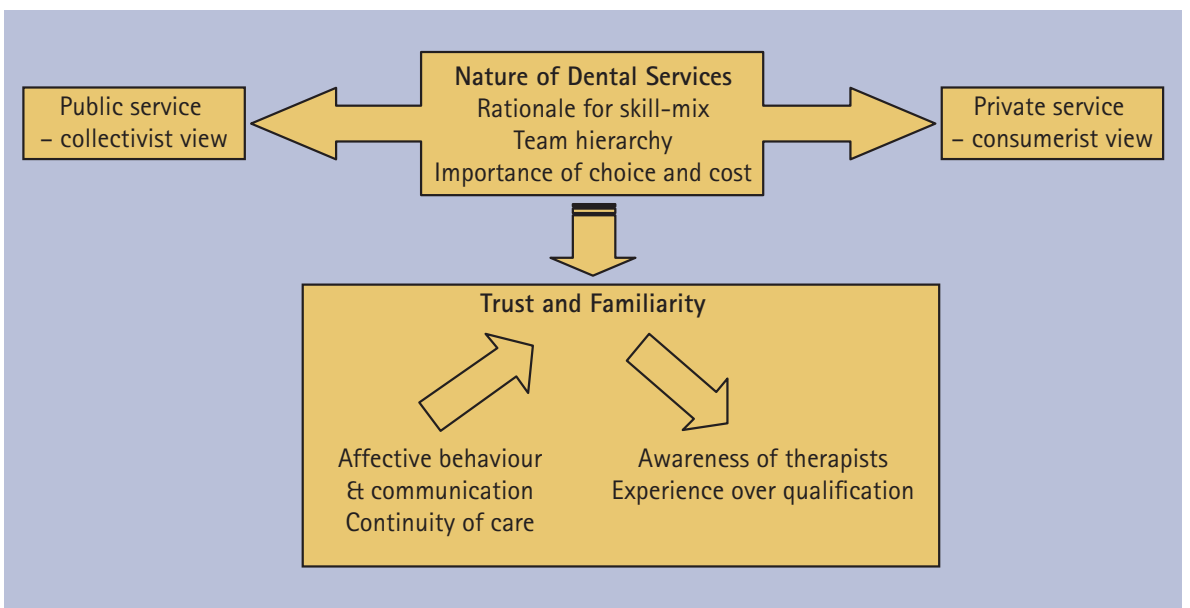

Fig. 1 Diagram of what matters to patients when their care is delegated to dental therapists

in line with recommendations. ${ }^{24}$ In all but one case this was at the participants' home and the other was at a neutral location.

Data collection involved narrative interviewing and ethnographic observation. Although initial questions were loosely framed around a topic guide, the interviews were largely unstructured, allowing participants the freedom to describe their experiences of care. This required the researcher to intervene as little as possible, but to use active listening techniques to invite additional storytelling. ${ }^{25,26}$ The researcher also used probing to clarify and encourage expansion on issues raised. ${ }^{27}$ At the end of each interview, the researcher summarised what had been said and provided an outline interpretation that was fed back to participants for confirmation.

Field notes taken during and after interviews informed the analysis. This included the researcher's interpretation of the interview alongside pauses, hesitations, facial expressions and other body language as reflections of participants' emotions that were not represented by speech alone. In addition, the notes provided the opportunity to interpret what had been said in the interview before transcription and analysis. ${ }^{26,28}$

Interviews were audio-recorded and transcribed verbatim by the researcher (TD) using standard transcribing equipment. During transcription, the observation notes were used to help re-familiarise the researcher with the encounter and to help with transcription and interpretation. Once transcribed, a synopsis of the interview and interpretation was then provided for each participant to check for inconsistencies and to confirm interpretations. This process is called 'member checking', which establishes the veracity of the research, and was undertaken either in person or by telephone, depending on participant preference. In all cases data were anonymised and false names assigned to protect the participant and the practice.

The transcripts were read and re-read a minimum of four times to identify the emergent themes within the stories. ${ }^{29} \mathrm{~A}$ more rigorous narrative thematic analysis was then undertaken..$^{26,30}$ In this form of analysis, sequences of data are preserved to keep stories intact for interpretive purposes, rather than coding small segments. ${ }^{30}$ Each transcript was analysed in turn and synopses were written to provide an account of the participants' personal characteristics and to summarise their views and experiences of having care delegated to a therapist. Where they emerged, intact narratives were then allocated under themes on an electronic database. This process was repeated for each interview until no new themes emerged. The key themes that emerged from the data are described, with quotations to illustrate the experiences and to facilitate readers' own interpretations.

Ethical approval was provided by the South Yorkshire Research Ethics Committee and Governance approval was provided by the health communities in which the study was undertaken.

\section{RESULTS}

Overall, participants held positive views of the use of skill-mix in dental practice and reported positive experiences of being treated by therapists. Two main themes emerged from the data that impacted on the acceptability of participants having their care delegated. The first has been 
termed: 'nature of dental services' and appeared to influence aspects of the second: 'trust and familiarity' (Fig. 1).

\section{Nature of dental services}

Participants' perceptions of the nature of dental services varied between and within individuals depending on the context in which dental services were being discussed. Views were arranged on a spectrum. At one pole a more public service perspective reflected more collectivist views of a dental service that served a community. The other extreme represented a more private service perspective consistent with a more consumer-orientated stance. Within this theme, three dimensions emerged: rationale for skill-mix; team hierarchy and importance of choice and costs. Each of these dimensions will now be described in turn with sections of narrative provided to support the interpretation.

\section{Rationale for skill-mix}

Views on the rationale for skill-mix centred on its potential to increase access to care and efficiency of services, in contrast, more public service views focused on meeting the health needs of the population:

'People are living longer and are keeping their teeth, there must be much more work... it means he can do the difficult stuff and the others [therapists] can take the easy stuff off his [the dentist] hands.' (Eric, 69)

Some public service views acknowledged that a reduction in cost might become a determining factor:

'I should say it's all down to money really. It usually is. It certainly was in my line of work. Even if something is a good idea for another reason but happens to cost less, it's usually the fact that it costs less that becomes the important thing.' (Margaret, 53)

More cynical consumerist views also centred on skill-mix's potential to cut costs:

'It's like all the NHS - it's on bankruptcy isn't it? And they've got to cut corners somewhere by doing it this way. I've no qualms about it really, but it's doing it on the cheap really, isn't it?' (Gary, 61)

Despite positive experiences of being treated by therapists, some suspected that employing them was mainly a business decision:

'If I were a dentist and I had a practice and I was private and I couldn't afford to employ all dentists because the costs would be too much, I would have to get something that's cost-effective.' (Ernest, 73)

While a spectrum between consumerist and public service approaches emerged from the narratives, there were also echoes of hierarchy of care with therapists being seen as employed to do the 'easy stuff' and perhaps not being accorded the same professional status as that of a dentist.

\section{Team hierarchy}

Many considered it important to have a dentist who is trusted as the head of a team.

'...they are a team... He's responsible for the whole team. As I say, if he recommends it then I would trust his judgement... Knowing somebody who you trust overseeing it all is really important.' (Peter, 45)

More extreme views within a particularly public service perspective saw little need for a hierarchy:

'... because I know she can do what I need without me having to go to see the dentist, you know, I can get to see them [the therapist] dead quickly, but I'd have to wait ages to see the dentist; they're always right busy.' (Linda, 35)

Whereas, more consumerist views tended to emphasise the importance of the dentist as a head of the team, preferring them to oversee treatment:

'Why have a dentist with the qualifications and the years of training and then go to have somebody else who isn't up there with them on a par really?' (Mary, 51)

In the same interview, this participant reported satisfaction with the care she had received and the technical competence of the therapist, highlighting the ambivalence of people's views:

'The hygienist [therapist] is the same really; she's really nice and chatty and also is careful with my gums - really grateful about that and it makes me happy to go back.' (Mary, 51)

\section{Importance of choice and cost}

Varying perspectives emerged concerning the importance of choice in relation to treatment provision and the cost if care is delegated to a therapist. Although satisfied with the care she had received, this participant took a consumerist approach to the right to choose clinicians:

'I think you ought to be given the choice... you might be quite happy to go to the hygienist [therapist] and have it done if it means that you can get a quicker appointment and it might be cheaper.' (Chrissie, 37)

In different circumstances the same participant saw the right to choose as something to be earned, exhibiting a meritocratic stance:

'Well, you know, if it means that people who can't afford to pay get to be treated, even if it's just like, you know, a therapist, well so what? Better something than nothing and if they can't pay, should they have a choice? I don't know.' (Chrissie, 37)

Other consumerist views saw skill-mix as an opportunity to create a scale of fees:

'I think you should pay proportionately to what skills are being used'. (Ernest, 73)

Many had not thought about issues of cost as they did not associate NHS charges with the treatment provided or the clinician providing the treatment. However, on further reflection, some questioned the logic of the current charging system:

'I would think that most people would expect to pay less of a charge for the same treatment... [pause] I don't know though because it might take the same amount of time - they're using the same equipment, same chemicals, so costs are the same... the therapist's time might be less, so I would expect to pay a little less.' (Gary, 61)

Strong public service views of dentistry were associated with a willingness to pay the same for treatment, whether provided by a dentist or a therapist in a NHS or private system:

'That's how it is. They're just doing the same job. If there was anything wrong she'd have to consult the dentist and he'd come and see and do whatever. That's okay with me [pause] I don't see anything wrong with it at all.' (Dennis, 57)

Despite high levels of satisfaction with care, consumerist perspectives saw choice of clinician and the costs of care as key issues in skill-mix use. In contrast, public service perspectives appeared to accept a team approach and associated charges with the procedure rather than the clinician performing it.

\section{Trust and familiarity}

The second key theme that appeared fundamental in the acceptability of skill-mix was trust and familiarity in the dental practice and team. This theme contained 
four dimensions that appeared to impact on (affective behaviour and communication; continuity of care), or were influenced by (awareness of therapists; experience over qualification) trust and familiarity (Fig. 1).

\section{Affective behaviour and communication}

One key factor in participants' trust in the dental team was the team's affective behaviour and communication. Where affective behaviour and communication were reported as being good, this appeared to build trust in the dental team, but where there was a perception of poor affective behaviour and communication, trust could be undermined (Fig. 1). Acceptance of delegation to therapists was related to trust in the dentist and based on experiences of care:

'When I went to [this] dentist, it was a different world... when I got there, there were people who were interested in what was going on, they talked me through treatments they were going to give to me, they told me exactly what they were going to do step-by-step, they kept checking that I was ok, that I was happy with everything. I found it very reassuring.' (Peter, 45)

Nonetheless, there was initial ambivalence to being treated by therapists if the rationale of skill-mix had not been communicated:

'Had he explained what the therapist did and how this affected the health of my teeth and gums etc, then I would have been more attentive and more prepared to accept what she said to me.' (Peter, 45)

Similar concerns were expressed where there was a high level of trust in the dentist and the patient had paid privately for treatment:

'Well I just thought it was all part of the same process of when you went for your check-up and it wasn't until I came to pay for it and I had to pay for both things that I realised it wasn't, which was a bit misleading because you had to pay another $£ 25$ for your hygienist [therapist], so going to the dentist was like a 50 quid outing.' (Chrissie, 37)

Despite being happy with care provided by therapists now, some reported negative experiences of being treated by hygienists or therapists, which appeared to emerge from a lack of communication both before and during an appointment:
'I mean, she used to just get on with it as if I was just another person she had to get through. She never had a nurse either so she was having to do it all herself really and there was water everywhere and sometimes it was difficult to tell her you needed a break or owt (sic), but she hardly ever spoke - not sure she was happy to be honest.' (Gary, 61)

Some emphasised the importance of communicating the rationale for delegating care and therapists' training, demonstrating a more consumerist perspective:

'I think there should definitely be boundaries and you've got to know these boundaries, you know? They should tell you, as a customer, you're not going to know these boundaries because you can't know the profession and you don't know what they can or can't do. Looking back, it could have been [explained] better, if he told me the reason why I was going to see the therapist. I mean, I now know whyand she has been right helpful in improving my gums and keeping my teeth clean...' (Mary, 51)

One suggestion was that therapists should be introduced to patients at the time that care is delegated and their remit and training should be explained by the dentist. One particularly collectivist participant had a very trusting, radical suggestion of how to approach this:

'I think it might help if they [therapists] actually do the consultation, you know, the check-up ... they would have more time to explain who they were and what they can do.' (Linda, 35)

It appears that where trust exists, a brief communication with patients about therapists' remit can be sufficiently reassuring to make skill-mix more acceptable:

'Well, he just said that he now has somebody working for him who specialised in the hygienist side of dentistry, so did I fancy going? I said yes.' (Margaret, 53)

\section{Continuity of care}

The other main factor influencing trust in the dental team was continuity of care. Although it was recognised that there can be a higher turnover of therapists, continuity of care from a dentist appeared to be critical in the acceptability of using skill-mix:

'The great thing for me at $X$ practice is that it's all under the same roof and I know the faces there. Although the hygienist or therapist has changed over the years, $\mathrm{Mr}$ $D$ is always there, so that's okay.'

This was in contrast to a past experience: 'I didn't know the dentist at $Y$, they kept changing, and I didn't know anything about hygienists, and when he said, 'oh, by the way, before you leave have a word with the hygienist' I thought who the hell's the hygienist?' (Peter, 45)

Reported bad experiences of dentistry appeared to lead to importance being placed on continuity of care (alongside affective behaviour) in establishing trust:

'I think that's how it should be whenever you go. Yes, seeing the same people, a stable staff, is really important for me. I don't know whether other people think the same... I think anyone's who's had a bad time at the dentist in the past is really keen to hang on to a dentist they like and is good.' (Edith, 59)

Trust in and continuity of care with a particular dentist could determine the practice attended, despite positive views being held about the practice's therapist:

'I mean at my practice I think there's [only my dentist] that's actually English - everyone is foreign... It's not that they're not English or British or whatever, I don't have a problem with that at all, it's cos you can't talk to them, which is useless if you've got a problem and they don't stay long, it seems to be like one in and one out all the time... I like to know who I'm seeing, if I couldn't see Mr Z, I would leave.' (Chrissie, 37)

\section{Awareness of therapists}

Overall, there was low awareness of dental therapists, illustrated by participants frequently referring to therapists as hygienists. Participants were unable to recount the dentist explaining the roles and training of a therapist:

'Well, I don't know, I thought she was a dentist, I didn't realise she was a therapist... I thought she was just like his, you know, young dentist he had set on, but no, I was impressed'. (Ernest, 73)

Trust in the dental team appeared to fill any knowledge gap and reduce the need to ask questions about therapists' training when their care was delegated:

'As I say, when the circumstance arose it was authorised by the dentist so I accepted that. With him knowing the person, knowing about the training she'd undertaken, 
if he was happy for her [the therapist] to do it, then that was good enough for me.' (Edith, 59)

Participants who had received extensive treatment from therapists were unaware of their training and permitted duties:

'To be honest, I don't know much about them. Are they just a nurse with extra training? I don't really know anything about them, which is a bit bad when you think she treats me regularly.' (Mary, 51)

Others presumed that therapists were 'specialists' in the treatment of children:

'No, he just refers them [the participant's children] straight through cos (sic) I think she's the one that deals with the kids more when they're having fillings and things. I don't think the dentists do that so much, and I think she is specialised in treating children, I think that's right.' (Linda 35)

A participant, who had healthcare workers in her family and insight into the training of healthcare professionals, admitted a lack of awareness, which, on reflection, she found disconcerting:

'I just thought they were just another dentist... maybe that was quite naive.' (Jenny, 38)

Whilst for others, trust in the referring dentist was the most important factor and relinquished the necessity to worry about who was providing care:

'Oh yes, she's some qualifications up in the surgery, what she's got-you know, this, that and the other, I don't really take much notice... I mean that's just me, taking the dentist on trust again isn't it?' (Dennis, 57)

\section{Experience over qualifications}

Regardless of the level of awareness of therapists as a professional group, for some people trust in the referring dentist, and experience of being treated by them, appeared more important than any qualifications they might have:

'If somebody is doing a job, you're not bothered who they are, it's not qualification, it's 'can they do the job?' that matters - you can have a string of qualifications and be rubbish.' (Ernest, 73)

Initially more negative views toward skill-mix were positively influenced by experiences:

'I just went with it as it was recommended by the dentist, but I did feel that it might be a waste of time and unnecessary. But that's in the deepest, darkest past now... with all the treatment I've had, it's absolutely great now.' (Peter, 45)

Similarly:

'...as long as she's competent, that's all that matters... in the end, does it really matter if they know what they're doing and they get the job done?' (Chrissie, 37)

Where preferences of only seeing the dentist existed, they appeared to be linked to anxiety about the unknown. Trust was a factor that enabled their agreement to see the therapists. Positive experiences when being treated by the therapist appeared to change views:

'Yeah, it changed my whole outlook on it definitely. I was a little bit taken by surprise but I accepted it - I let her get on with it, I had no bad feelings about it and she did a good job and I wouldn't have any qualms about having my children go see them now, I don't think, back in the 60s, when my kids were small, I would have been a little more apprehensive, I think. But not now, I think having experienced that it wouldn't worry me.' (Gary, 61)

\section{DISCUSSION}

To our knowledge, this is the first study to explore the views and experiences of adult patients, and parents of child patients, who had their care delegated to therapists. Overall, these participants reported positive experiences of either themselves or their children being treated by them. These findings complement and are consistent with existing quantitative patient satisfaction data, which suggest that patients treated by therapists are at least as satisfied with their care as they are with dentists. ${ }^{11,15}$ However, the findings corroborate concerns from general healthcare that reports of high levels of patient satisfaction identified in surveys can mask areas of concern. ${ }^{18-21}$ Using qualitative research has enabled deeper exploration of patients' experiences, identifying what matters to patients when their care is delegated.

The perception of the nature of dental services was found to be important in our earlier study of adults who had not been treated by therapists. Collectivist, public sector views of dentistry tended to be more supportive of the idea of skill-mix than more consumerist, private service perspectives. ${ }^{14}$ However, these data suggest that a consumerist stance does not preclude the use of skill-mix. Dental teams considering its use should be conscious that such perspectives may see the adoption of skill-mix as an opportunity for financial gain or cost saving. Consequently, a brief explanation of the rationale would be wise. In addition, reassurances of the training, permitted duties and requirements of supervision would appear necessary.

Although the most collectivist views saw no need for a dentist to diagnose and prescribe treatment, a team hierarchy was seen as important, with reassurance provided by a dentist (whom they trusted) overseeing treatment and ideally working in the same building. These findings have implications for current UK debates concerning therapists being permitted to work without indirect supervision (where a dentist diagnoses, treatment plans but does not evaluate all patients) ${ }^{31}$ in independent practices, as they do in other parts of the world.

An important finding of this research was how trust and familiarity in the dentist and team delegating care to therapists was critical in patients' views of skill-mix. It appears that such trust and familiarity is built on the affective behaviour, communication of the team and the continuity of care. The importance of these factors is perhaps unsurprising given that they have been previously identified as determinants of patient satisfaction in general healthcare $^{18}$ and dentistry ${ }^{32}$ and patients' perceptions of the ideal dentist. ${ }^{33,34}$ Participants described their dentists as having a 'good chairside manner' and the whole team taking an interest in their well-being. These data support the continued emphasis of communication skills in undergraduate and postgraduate teaching and training and the importance of patient-centred approach in practice.

Patients' trust in clinicians should not be underestimated or abused. For these people, the high levels of trust in referring dentists meant that patients accepted referrals to a clinician about whom they knew very little in terms of their training and permitted duties. Clearly this has implications for ethical practice when skill-mix is being used, particularly relating to the imperative of valid consent in team working. ${ }^{35}$

Strong views were held on the continuity of care; some participants would move practices if their dentists left. Turnover of dentists and other team members will undermine 
continuity of care and therefore trust. It is worth noting that the only negative experiences reported by participants were from practices where staff turnover was perceived to be high and communication poor. Not only should dental care providers monitor staff turnover, it may be a useful indicator for contract quality monitoring.

Statistical generalisations cannot be inferred from qualitative research; however, conceptual generalisations can be made. Consequently, the key themes identified are likely to be present among patients in other areas of the country, but a larger study would be needed to quantify the extent to which these views are held. Practices were asked to identify those who declined to see a therapist after an initial visit, but none were able to identify a patient willing to be interviewed. Thus the universally positive experiences of being treated by therapists are likely to be a consequence of recruiting patients being treated by them rather than those who declined. Research ethics and the study protocol did not permit followup of potential participants who initially declined involvement. Any future research should aim to include such patients' views. Interestingly, the referring dentists in these practices cited complaints of discomfort during scaling as the main reason for patients declining further referrals to the therapist.

A second concern was the similarity of the practices that participated. Given the lack of incentives of using skill-mix in the current NHS contract, those employing it are unlikely to be typical. Moreover, there was a sense from the data and from direct contact with the dentists that the practices had a particularly patient-centred approach. Nonetheless, qualitative methods were able to identify areas for improvement in the process of delegation, particularly in the communication of its rationale and the training and permitted duties of therapists.

\section{CONCLUSION}

This study of adult patients and parents of child patients, who held positive views of being treated by therapists, indicates that care can be delegated acceptably in many cases. Trust in, and familiarity with, the dental team appeared to be critical, with trust seemingly determined by affective behaviour, communication and continuity of care. These findings have profound implications for skill-mix use where staff turnover is high as familiarity, continuity of care and, therefore, trust may be compromised.

The authors would like to acknowledge the British Society of General Dental Surgery who provided financial support for this study from their Scholarship Award. TD drafted the research protocol, undertook all data collection, transcription and led the analysis. JO and PGR supported the drafting of the protocol and analysis. All three authors contributed to the report of the research.

1. Nuffield Foundation. Education and training of personnel auxiliary to dentistry. London: Nuffield Foundation, 1993.

2. General Dental Council. The report of the Dental Auxiliary Review Group. London: GDC, 1998.

3. Department of Health. The dental auxiliaries (amendment) regulations 2002. Statutory Instrument 2002: UK Parliament, 2002.

4. Department of Health. Modernising NHS dentistry implementing the NHS plan. London: DH, 2000.

5. Department of Health. NHS dentistry: options for change. London: DH, 2002.

6. Department of Health. NHS dental services in England: an independent review led by Professor Jimmy Steele. London: DH, 2009.

7. Evans C, Chestnutt I G, Chadwick B L. The potentia delegation of clinical care in dental practice. $\mathrm{Br}$ Dent J 2007; 203: 695-699.

8. Bramson J B, Guay A H. Comments on the proposed pediatric oral health therapist. J Public Health Dent 2005; 65: 123-127.

9. Maxwell R J. Quality assessment in health. Br Med J (Clin Res Ed) 1984: 288: 1470-1472.

10. Donabedian A. An introduction to quality assurance in health care. New York: Oxford University Press, 2002

11. Galloway J, Gorham J, Lambert M et al. The professionals complementary to dentistry: a systematic review and synthesis. London: University College London, Eastman Dental Hospital, Dental Team Studies Unit, 2002

12. Nash D A, Friedman J W, Mathu-Muju K R et al. A review of the global literature on dental therapists In the context of the movement to add dental therapists to the oral health workforce in the United States. W K. Kellogg Foundation, 2012.

13. Dyer T A, Humphris G, Robinson P G. Public awareness and social acceptability of dental therapists. Br Dent J 2010; 208: E2; discussion 16-17.
14. Dyer T A, Robinson P G. Exploring the social acceptability of skill-mix in dentistry. Int Dent J 2008; 58: 173-180.

15. Sun N, Burnside $G$, Harris R. Patient satisfaction with care by dental therapists. Br Dent J 2010; 208: E9.

16. Locker D, Dunt D. Theoretical and methodological issues in sociological studies of consumer satisfaction with medical care. Soc Sci Med 1978; 12: 283-292.

17. Bury M. Health and illness in a changing society. London: Routledge, 1997

18. Sitzia J, Wood N. Patient satisfaction: a review of issues and concepts. Soc Sci Med 1997: 45: 1829-1843.

19. Calnan M. Towards a conceptual framework of lay evaluation of health care. Soc Sci Med 1988: 27: 927-933.

20. Schneider H, Palmer N. Getting to the truth? Researching user views of primary health care. Health Policy Plan 2002; 17: 32-41.

21. Meissner H I. Use of qualitative methods to ensure acceptability of interventions. J Public Health Dent 2011; 71: S83.

22. Bowling A. Research methods in health: investigating health and health services. 2nd ed. Maidenhead: Open University Press, 2002

23. Tashakkori A, Creswell J W. The new era of mixed methods research. J Mix Method Res 2007; 1: 3-7.

24. Denzin N K, Lincoln Y S (eds). The SAGE handbook of qualitative research. 3rd ed. California: SAGE, 2005.

25. Chamberlayne P, Rustin M, Wengraf T (eds). Biography and social exclusion in Europe: experiences and life journey. Bristol: Policy Press, 2002.

26. Squire C. Experience-centred and culturally oriented approaches to narrative. In Andrews M, Squire C, Tamboukou M (eds) Doing narrative research. London: SAGE, 2008.

27. Chase S E. Narrative inquiry. Multiple lenses, approaches, voices. In Denzin N K, Lincoln Y S (eds) The SAGE handbook of qualitative research California: SAGE, 2005

28. Owens J. Liberating voices through narrative methods: the case for an interpretive research approach. Disabil Soc 2007; 22: 299-313.

29. Sparkes A C. Narrative analysis: exploring the whats and hows of personal stories. In Holloway I (ed) Qualitative research in health care. pp 191-209. Buckingham: Open University Books, 2005.

30. Riessman C K. Narrative methods for the human sciences. London: SAGE, 2007.

31. Burt B A, Eklund S A Dentistry dental practice and the community. 6th ed. St. Loius: Elsevier Saunders, 2005.

32. Newsome PR, Wright G H. A review of patient satisfaction: 2. Dental patient satisfaction: an appraisal of recent literature. Br Dent J 1999; 186: 166-170.

33. Lahti $S$, Tuutti $H$, Hausen $H$, Kääriäinen R. Dentist and patient opinions about the ideal dentist and patient - developing a compact questionnaire. Community Dent Oral Epidemiol 1992; 20: 229-234.

34. Lahti $S$, Tuutti H, Hausen $H$, Kääriäinen R. Patients' expectations of an ideal dentist and their views concerning the dentist they visited: do the views conform to the expectations and what determines how well they conform? Community Dent Oral Epidemiol 1996: 24: 240-244.

35. General Dental Council. Principles of dental team working. London: GDC, 2009. 